\title{
ELECCIONES EN HAMBURGO
}

Siguiendo la tendencia marcada en las últimas elecciones a los Parlamentos de los Länder, el gran perdedor de los comicios al Senado berlinés celebrados el 5 de junio ha vuelto a ser el partido del Gobierno. La SPD obtuvo el peor resultado

\section{ELECCIONES EN HAMBURGO EN LOS ULTIMOS VEINTICINCO AÑOS}

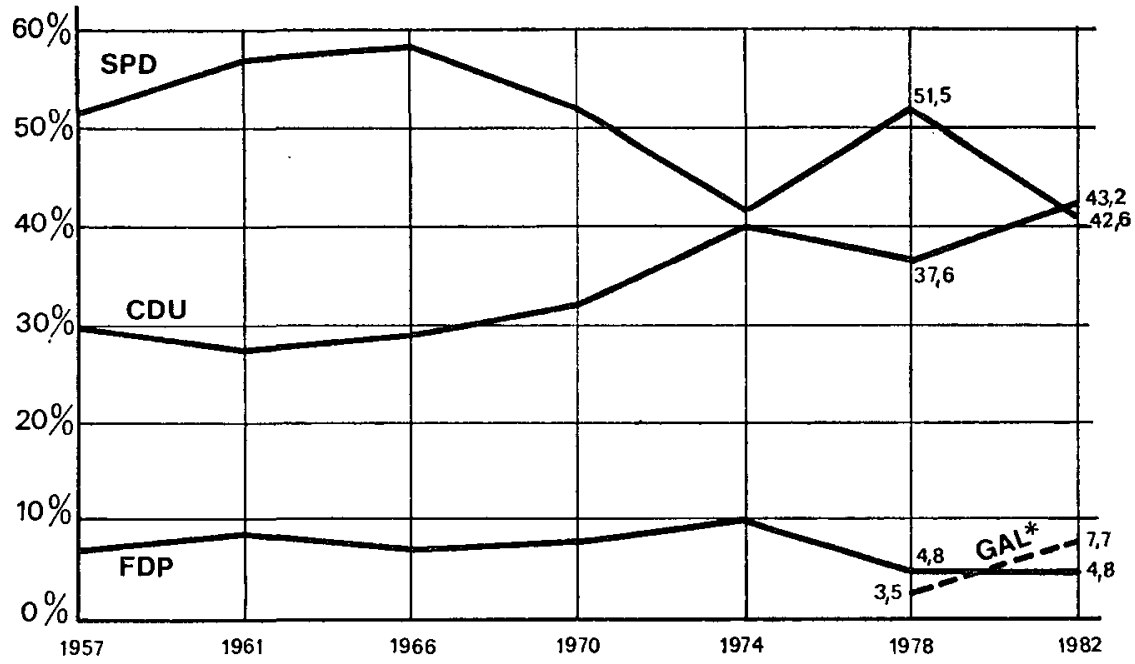

* Lista verde (ecologistas) y alternativa.

desde 1949 en uno de sus «feudos» tradicionales, ciudad además de la que procede el propio canciller Schmidt: los socialdemócratas, dirigidos por un candidato de indudable calidad política y humana - Klaus von Dohnanyi- descendieron un 8,7 por 100 y han perdido catorce diputados. En las elecciones al Senado berlinés la pérdida de votos hace ahora un año fue del 4 por 100 , y del 6 por 100 en 
la Baja Sajonia: la tendencia no solo se mantiene, se agudiza. De los 35.000 votos perdidos por la SPD han ido a parar 23.000 a los cristianodemócratas $(43,2$ por 100,56 diputados), y 12.000 electores socialdemócratas se decidieron esta vez por la Lista Verde y Alternativa (GAL: 7,7 por 100, nueve diputados). Los liberales volvieron a obtener el mismo resultado de 1978 , el 4,8 por 100 , lo que les vuelve a situar fuera del Senado. Nada más conocidos los resultados de las elecciones, Schmidt se apresuró a manifestar que su destino político no se halla unido al de Hamburgo. Las consecuencias políticas de las tres últimas elecciones para la coalición socialdemócrata-liberal en Bonn no se han hecho esperar: coalición de los liberales con la CDU en Hesse para las elecciones del 26 de septiembre, y críticas en el seno de la SPD contra la línea mantenida por los órganos directivos del partido. A pesar de la aparente unanimidad demostrada en el Congreso socialdemócrata en Munich - consigna: «cerrar filas tras el Kanzler»-, los grupos favorables a una apertura hacia los ecologistas aumentan en el seno de la SPD. Por su parte, los «verdes» se hallan representados ya en cinco parlamentos regionales; llevan camino de convertirse en el partido-balanza a nivel federal. Aunque bien pudiera ocurrir en Bonn lo que ahora mismo está sucediendo en Hamburgo: la ciudadEstado se ha convertido en ingobernable a causa de la negativa de los ecologistas a formar coaliciones con cualquiera de los dos partidos mayoritarios. No queda más solución que un gobierno minoritario de la CDU o la convocatoria de nuevas elecciones, supuesto éste absolutamente extraño en la vida política alemana y visto por algunos observadores como fraude a los electores.

En conclusión: para la República Federal Alemana se abre una época de difícil gobernabilidad y de radicalización de las opciones políticas que puede abocar en una profunda crisis de Estado.

José María Beneyto 